\title{
REFLEXÕES SOBRE A ÉTICA DO CUIDADO E A EDUCAÇÃO POPULAR
}

\author{
REFLEXIONS ABOUT THE ETHIC CARE AND POPULAR EDUCATION \\ REFLEXIONES SOBRE EL CUIDADO ÉTICO Y LA EDUCACIÓN POPULAR
}

\author{
Dafiana do Socorro Soares Vicente-Carlos \\ E-mail: daffyanna@gmail.com \\ Erenildo João Carlos \\ E-mail: erenildojc@gmail.com \\ Universidade Federal da Paraíba - UFPB
}

\begin{abstract}
RESUMO
O texto objetiva refletir sobre a questão ética e a educação popular (EP) a partir do conceito de ética do cuidado formulado por Santos (2002). Em face dessa referência, compartilhamos da hipótese de que a ética é uma dimensão constituinte da existência da EP como prática social particular. Entendemos o princípio ético como a força motriz que anima o fazer educativo e o pedagógico da EP, envolvidos com as lutas dos velhos e dos novos movimentos sociais de vários setores progressistas da sociedade civil organizada, e serve de fonte do compromisso e da responsabilidade sociopolítica de educadores e educadoras populares.
\end{abstract}

Palavras-chave: Ética do cuidado. Educação Popular. Dignidade do ser humano.

\begin{abstract}
The aim of the text is reflect about the ethic question and popular education (PE) starting with the concept of ethic care formulated by Santos (2002). Facing this reference, we share the hypothesis that the ethic is a constituent dimension of $P E$ existence as the particular social practice. We understand the ethical principle as the driving force who encourage the educational and pedagogical role of the PE, involved with old and new struggles of social movements in several progressive sectors of organized civil society, and suits as source for commitment and sociopolitical responsibility of popular educators.
\end{abstract}

Keywords: Ethic care. Popular education. Human being dignity.

\section{RESUMEN}

El objetivo del texto es reflexionar sobre la cuestión ética y la educación popular (PE) a partir del concepto de ética del cuidado formulado por Santos (2002). Frente a esta referencia, compartimos la hipótesis de que la ética es una dimensión constitutiva de la existencia de PE como la práctica social particular. Entendemos el principio ético como la fuerza motriz que fomenta el papel educativo y pedagógico de la EF, involucrado en las luchas antiguas y nuevas de los movimientos sociales en varios sectores progresistas de la sociedad civil organizada, y se adapta como fuente de compromiso y responsabilidad sociopolítica de los educadores populares.

Palabras-clave: Ética del cuidado. Educación popular. Dignidad del ser humano.

\section{Introdução}

Resolvemos nomear este texto de reflexivo porque ele não tem a pretensão de ser visto como um ensaio sobre a questão da relação entre ética e educação popular (EP). Esse é um desejo que, por ora, ficará suspenso, por exigir mais aprofundamentos e uma atenção mais acurada e rigorosa de nossa parte, o que, no momento, não é possível realizar. Com efeito, trata-se, tão 
somente, do registro de alguns achados que encontramos no curso da leitura, do estudo e da investigação empreendida sobre a questão em tela.

Ademais, ancorando-nos na noção de ética do cuidado cunhada por Santos (2002), consideramos este texto como uma produção analítico-argumentativa, que sistematiza leituras, achados e reflexões de forma articulada, com o intuito de exercitar a defesa da tese anunciada em seu título - a de que a ética é uma dimensão da EP. A reflexão recorre tanto a elementos teóricoconceituais quanto histórico-sociais, pautados em exemplos de lutas e em perspectivas assumidas por setores populares e diversos sujeitos da sociedade civil organizada no Brasil.

\section{Sobre a noção de ética e ética do cuidado}

Sabe-se que a ética se assenta no reconhecimento do ser humano, de sua vida e de sua dignidade. Nesse sentido, ela é fundada no entendimento de que sua razão de ser encontra-se no fato de o ser humano existir como tal. Em outros termos, a ética seria uma representação valorativa do reconhecimento da existência humana como algo real, irrefutável e necessário, um tipo de consciência que possibilita ao ser humano se ver como ser humano.

Essa ideia é imprescindível para o estabelecimento da diferença entre a consciência ética e a consciência moral. Enquanto a ética se refere ao gênero humano e à possibilidade de desenvolver sua humanidade, a moral está intimamente relacionada ao campo do cumprimento das normas, mais precisamente, ao conjunto de valores aceitos como legítimos por determinados grupos sociais. Nesse sentido, a moral sempre é relativa, afeita ao modo como determinados grupos regulam a consciência e a conduta de seus membros e ao funcionamento da rede de relações tecidas no contexto de suas formações sociais. ${ }^{1}$

Esse entendimento de ética e de moral, além de proporcionar a diferença entre elas, serve como critério de verificação e avaliação dos tipos de valor acolhidos e compartilhados por determinados grupos e sociedades. Isso aponta para a possibilidade de existirem valores morais não humanos, deveres estabelecidos, incompatíveis com os valores de natureza ética. Considerando esse entendimento, podemos dizer que um saber, uma experiência, uma prática, uma luta, um discurso, uma ideologia, uma teoria ou uma concepção de mundo caracterizam-se como ética quando têm como ponto de partida e de chegada e como centro articulador o valor supremo, absoluto e indiscutível do ser humano.

1 Sobre a questão do agir moral, sugerimos a leitura de Carlos, D.; Carlos E. (2015).

\begin{tabular}{l|l|l|l|l|l} 
C Revista Triângulo & Uberaba, Minas Gerais & v.12 & n.1 & p. 68 - 84 & 2019
\end{tabular}


Em Santos (2002), por exemplo, a questão ética é colocada como uma espécie de critério do exercício da crítica e um princípio das lutas relativas à emancipação social dos povos. Nessas condições, parece-nos que Santos apresenta uma via de entendimento sobre a questão ética que, a nosso ver, indicaria um modo parecido com as intervenções culturais e políticas da educação popular realizadas no seio das lutas dos movimentos sociais e populares ${ }^{2}$. Trata-se de uma concepção de ética assentada no cuidado com o governo dos homens e das coisas, como ressalta Santos (2002, p. 256-257):

[...] a sociologia das emergências substitui a ideia de determinação pela ideia axiológica do cuidado. A axiologia do progresso é, assim, substituída pela axiologia do cuidado. Enquanto na sociologia das ausências a axiologia do cuidado é exercida em relação às alternativas disponíveis, na sociologia das emergências é exercida em relação às alternativas possíveis. Esta dimensão ética faz com que nem a sociologia das ausências nem a sociologia das emergências sejam sociologias convencionais [...].

A 'axiologia do cuidado', entendida como uma dimensão ética, ajuda-nos a pensar no trabalho político-pedagógico da EP, seja no que diz respeito ao seu fazer crítico, seja no que tange à sua prática comprometida com os processos de libertação e de humanização dos segmentos marginalizados e oprimidos. Do ponto de vista do fazer crítico da EP, a ética do cuidado, sugerida por Santos, possibilita um trabalho de análise, desconstrução e rejeição de certas noções que sustentam a visão convencional de sociedade. Assinalamos, resumidamente, seis pontos relevantes no âmbito de nossa reflexão.

Em primeiro lugar, podemos dizer que uma das noções fundantes do processo de crítica sugerido por Santos diz respeito ao acolhimento do conceito de 'Ainda-não', que [...] exprime o que existe apenas como tendência, um movimento latente no processo de se manifestar [...]. Dito de outra maneira, [...] o Ainda-não é, de um lado, capacidade (potência) e, de outro, possibilidade (potencialidade) [...]. O caráter crítico dessa noção se encontra no fato de que ela possibilita que, a um só tempo, reconheçamos a riqueza das experiências emancipatórias e humanizantes existentes no presente e a possibilidade de que elas continuem se expandindo e se desenvolvendo no futuro. Assim, ao invés de apontar [...] um futuro vazio e infinito [...], esse conceito sugere [...] um futuro concreto [...], mas [...] sempre incerto e sempre em perigo [...] (SANTOS, 2002, p. 256).

\footnotetext{
2 Sobre a questão especifica dos modos de entendimento da educação popular, ler Carlos (2003) e Alcantara; Carlos (2018).
} 
Em segundo lugar, a incerteza produzida pelo conceito Ainda-não gera uma consequência importantíssima, a saber: o fato de que ela põe em cheque uma das noções fundantes da modernidade, ou seja, a noção de tempo linear, cuja base se assenta na [...] ideia de que a história tem sentido e direção únicos e conhecidos [...]. Vale destacar que essa noção tem assumido várias designações no campo do discurso, da visão de mundo e do saber elaborado pela razão indolente, como [...] progresso, revolução, modernização, desenvolvimento, crescimento e globalização [...] (SANTOS, 2002, p.247). Assinala o autor que o ponto comum entre "[...] essas formulações é a ideia de que o tempo é linear e que na frente do tempo, seguem os países centrais do sistema mundial e, com eles, os conhecimentos, as instituições e as formas de sociabilidade que eles dominam [...]" (Idem, p.247).

Santos assevera que a noção de tempo linear, definidora da visão convencional de sociedade, não deve ser entendida como algo intrínseco à natureza da cultura ou da sociedade, para que sua duração não pudesse ser organizada de forma diferente. Ao contrário disso, “[...] o tempo linear é uma entre muitas concepções do tempo [...]" e que essa "[...] foi a concepção adotada pela modernidade ocidental a partir da secularização da escatologia judaico-cristã [...]” (SANTOS, 2002, p. 251). Então, o reconhecimento da existência efetiva de várias alternativas de temporalidades aponta o fato de que a modernidade ocidental assumiu o tempo linear como parâmetro em detrimento de outras opções. Em terceiro lugar, a crítica do tempo linear sobre a ideia de que o futuro é abundante e infinito e que as faltas de hoje certamente serão atendidas amanhã, é consubstanciada no conhecimento cotidiano de que há um vazio, uma distância insuperável entre a concepção do tempo linear, que fundamenta a noção histórica de progresso, de desenvolvimento e de revolução, e a experiência concreta do tempo de vida do indivíduo. Isso significa que o tempo histórico linear e a expectativa de vida individual têm uma duração distinta, profundamente incompatível entre si. O indivíduo morre antes de realizar seu sonho. O sonho e a experiência concreta de uma vida melhor são profundamente distantes e inconciliáveis na perspectiva convencional, forjada pela razão indolente.

Em quarto lugar, o fato de se reconhecer que o futuro é incerto, ou seja, a expectativa de que, no amanhã, possamos ter uma experiência de vida abundante, melhor do que a que temos hoje, alimenta a dúvida real de que as promessas de uma vida boa aconteçam. Porém essa dúvida, ao invés de ser um pensamento que gera paralisia e falta de esperança e de expectativas, faz emergir a consciência de que o futuro nos pertence, de que ele será o que fazemos hoje e de que se inscreve 
por meio das ações que empreendemos a seu favor. Em outras palavras, devido à incerteza gerada por essa contradição, é necessário cuidado. Santos (2002, p. 257) refere que

[...] cuidar do futuro é imperativo porque é impossível blindar a esperança contra a frustração, o advento contra o niilismo, a redenção contra o desastre, em suma, porque é impossível a esperança sem a eventualidade do caixão [...].

Em quinto lugar, a natureza do conceito do Ainda-não contempla uma dimensão por meio da qual se pode identificar algo no presente que existe em potência, mas que ainda não se pode saber se, no futuro, será, de fato, um acontecimento. $\mathrm{O}$ caso de ser potência no presente e possibilidade no futuro oferece a consciência da incerteza, do risco e de sua não efetividade futura e desenha um horizonte de perspectivas e expectativas, de sonhos e de utopias não fantasiosos, não imaginários e não ilusórios, forjados nas experiências concretas do aqui-e-agora, cujas vivências individuais e coletivas confirmariam a existência de experiências, de práticas e de agentes bem sucedidos, no que tange a propiciar o acesso a uma vida pautada na dignidade humana e o usufruto dela.

Esse reservatório e esse acúmulo de alternativas eticamente exitosas disponíveis é que indicariam uma tendência de que poderemos ter um futuro mais promissor. São essas alternativas reais, concretas e exitosas que deveriam ser mais bem conhecidas, a fim de que possamos "[...] maximizar a probabilidade da esperança, em relação à probabilidade da frustração [...]” e "[...] definir princípios de ação que promovam a realização dessas condições [...]” (SANTOS, 2002, p. 256) eticamente disponíveis hoje e, portanto, possíveis amanhã. Conforme esclarece Santos (2002, p. 256),

[...] a sociologia das emergências é a investigação das alternativas que cabem no horizonte das possibilidades concretas. Enquanto a sociologia das ausências amplia o presente, juntando ao real existente o que dele foi subtraído pela razão metonímica, a sociologia das emergências amplia o presente, juntando ao real amplo as possibilidades e expectativas futuras que ele comporta [...].

A axiologia do cuidado e seu desdobramento em atividade de vigilância e de produção do futuro possível fazem do cuidado ético o parâmetro da crítica e da contraposição à lógica da razão indolente e de sua racionalidade metonímica e proléptica, que organizam as relações sociais a partir de parâmetros excludentes, impositivos, violentos e dominadores. Podemos dizer que a vigilância ética, entendida como um princípio centrado no cuidado, sugere uma crítica a esses dois modos de existir da razão indolente.

No primeiro sentido, tem-se a crítica à racionalidade metonímica, à sua tendência à 
exclusão, devido à ênfase que confere ao pensamento único e à eliminação de todas as alternativas, seja do ponto de vista do seu silenciamento, da impossibilidade de existir ou de sua ressignificação em função dos parâmetros e dos critérios, que a racionalidade metonímica define como corretos, como paradigmas. No segundo, a vigilância contra a racionalidade proléptica, no sentido de que ela é prospectiva, um projeto de futuro que é incerto, duvidoso, muitas vezes, improvável e impossível. Nesse mesmo movimento de projeção para o futuro de algo incerto, ela desloca nosso olhar para os contextos, as experiências concretas, as vivências que tem proporcionado no tempo da história presente e do cotidiano das comunidades, dos movimentos, das ONGs, como evidências. Isso demonstra que existem outras formas de produção e de organização social voltadas para o desenvolvimento humano, para a felicidade e a qualidade de vida dos indivíduos e dos grupos sociais.

A crítica a essas duas formas de racionalidade é um exercício de pensar ético no que diz respeito ao cuidado contra práticas sociais e relações sociais produtoras do sofrimento e indutoras de uma lógica do sacrifício do presente, de experiências cotidianas, existenciais e concretas, em que a humanidade do ser humano é negada. Contra esse estado de coisas, Santos (2002, p. 258) refere que a axiologia do cuidado exige [...] uma vigilância ética constante sobre o desenrolar das possibilidades, servida por emoções básicas como o espanto negativo que suscita a ansiedade e o espanto positivo que alimenta a esperança [...]. Possibilidade de uma qualidade de vida experimentada no e aqui e agora, ou seja, num espaço-tempo da história presente, e não, num futuro distante, concebido imaginária e utopicamente a partir da incerteza do amanhã, forjada por um projeto de sociedade orientado pela visão de mundo que é alimentada pela razão indolente. De acordo com Santos (2002, p. 255),

[...] o Ainda-não inscreve no presente uma possibilidade incerta, mas nunca neutra; pode ser a possibilidade da utopia ou da salvação (Heil) ou a possibilidade do desastre ou perdição (Unheil). Esta incerteza faz com que toda a mudança tenha um elemento de acaso, de perigo. É esta incerteza que, em meu entender, ao mesmo tempo em que dilata o presente, contrai o futuro, tornando-o escasso e objeto de cuidado. Em cada momento, há um horizonte limitado de possibilidades e por isso é importante não desperdiçar a oportunidade única de uma transformação específica que o presente oferece: carpe diem [...]. (O grifo é nosso)

\section{Exemplos da ética do cuidado na educação popular}


Parece-nos que a questão ética e a educação popular passam por uma diversidade de vias e possibilidades efetivas, conforme assinala Hurtado (2006, p. 157-155), ao indicar uma série de aspectos com os quais a educação popular se envolve e se implica, como o aspecto ético, por exemplo, visto como princípio orientador dos demais aspectos de sua prática social. O princípio ético contribui para promover a transformação social, tanto por meio das ações dos educadores quanto dos educandos; o epistemológico, cujo processo de produção e de compartilhamento de conhecimentos é colocado como um dispositivo de resistência e transformação das formas de controle e de dominação, bem como de libertação, autonomia e criticidade; o pedagógico, vinculado à reflexão e à prática educativa articulada a processos democráticos e democratizadores; por fím, $\mathrm{o}$ sociopolítico, considerado como uma dimensão relacionada às questões do poder compartilhado, como forma de relações sociais específicas.

Essas esferas da EP podem funcionar como um roteiro, uma espécie de mapa que nos possibilita adentrar a questão central do nosso interesse que é a ética, entendida como ética do cuidado. No que tange à via do conhecimento ou, mais precisamente, dos processos de produção do conhecimento assumido no seio da educação popular, pelos diversos sujeitos ou agentes populares no curso de suas reivindicações lutas, a ética do cuidado passa, necessariamente, pelo exame crítico das metodologias de pesquisa com as quais a EP deveria trabalhar. Entende-se que a questão ética poderia e deveria ser um critério paradigmático de produção do conhecimento e de suas implicações sociais. Considerando esse ponto, Santos (2002, p. 238) alerta:

[...]. Sem uma crítica do modelo de racionalidade ocidental dominante pelo menos durante duzentos anos, todas as propostas apresentadas pela nova análise social, por mais alternativas que se julguem, tenderão a reproduzir o mesmo efeito de ocultação e descrédito [...].

É nesse contexto de crítica à racionalidade dominante, designada de 'indolente', que Santos apresenta a 'sociologia das ausências' e a 'sociologia das emergências' como um dispositivo de análise crítica da referida razão, cujos modos de existência ocorreriam, segundo o Santos (2002, p. 239-240), de quatro maneiras:

[...] a razão impotente, aquela que não se exerce porque pensa que nada pode fazer contra uma necessidade concebida como exterior a ela própria; a razão arrogante, que não sente necessidade de exercer-se porque se imagina incondicionalmente livre e, por conseguinte, livre da necessidade de demonstrar a sua própria liberdade; a razão metonímica, que se reivindica como a única forma 
de racionalidade e, por conseguinte, não se aplica a descobrir outros tipos de racionalidade ou, se o faz, fá-lo apenas para as tornar em matéria-prima; e a razão proléptica, que não se aplica a pensar o futuro, porque julga que sabe tudo a respeito dele e o concebe como uma superação linear, automática e infinita do presente $[\ldots]$.

Nessas condições, uma estratégia do cuidado seria a de analisar as experiências exitosas disponíveis e possíveis, cuja potencialidade sinaliza uma tendência de ocorrer novamente no futuro tal como ocorre no presente. Assim, o cuidado com o futuro não seria a expressão de um gesto utópico, fantasioso e ilusório, representante de uma realidade futura imaginária, cujas condições efetivas não existem hoje em lugar nenhum. Ao conceber um futuro fundado no aqui e no agora das experiências disponíveis e possíveis, trabalha-se com uma expectativa realista e utópica, cuja representação simbólica funda-se no Ainda-não, ao invés do Nada. Santos (2002, p. 258) assevera que

[...] a amplificação simbólica operada pela sociologia das emergências visa analisar numa dada prática, experiência ou forma de saber o que nela existe apenas como tendência ou possibilidade futura. Ela age tanto sobre as possibilidades como sobre as capacidades. Identifica sinais, pistas ou traços de possibilidades futuros em tudo o que existe. Também aqui se trata de investigar uma ausência, mas enquanto na sociologia das ausências o que é activamente produzido como não existente está disponível aqui e agora, ainda que silenciado, marginalizado ou desqualificado, na sociologia das emergências a ausência é de uma possibilidade futura ainda por identificar e uma capacidade ainda não plenamente formada para a levar a cabo $[\ldots]$.

Pensando com Carrilho, emerge a perspectiva de que, ao longo de sua história, a EP foi ampliando seu horizonte e seu diálogo com diferentes vertentes epistemológicas, sobretudo as de cunho qualitativo, que são mais afeitas e próximas dos problemas existenciais em que vivem os segmentos populares. Carrilho trabalha com a ideia de que a EP aprendeu a dialogar com várias metodologias de pesquisa tendo em vista as necessidades de cada sujeito popular, desde que tivesse comprometimento com os segmentos oprimidos e marginalizados, seja na perspectiva de que relacionar o conhecimento com os processos específicos de humanização e libertação desses sujeitos sociais seja para conferir visibilidade às suas experiências, suas historias, seus saberes, suas práticas, suas expectativas e suas necessidades concretas.

Carrilho assevera que, na América Latina, a EP optou, sobretudo, por se afinar com metodologias de pesquisa que colaborem com a produção de conhecimentos afeitos às lutas dos 
sujeitos populares, como, por exemplo, metodologias participativas, como a pesquisa-ação participativa, a recuperação da história coletiva, os diagnósticos participativos e a sistematização de experiências. Essas metodologias de pesquisas etnográficas inserem o pesquisador no mundo da vida dos oprimidos, dos excluídos, dos marginalizados e dos explorados, a fim de estabelecer com eles contatos e conhecê-los ao mesmo tempo em que aprende com eles.

Exemplo histórico advém da experiência originada com a educação de jovens e adultos, mais especificamente, com a alfabetização de jovens e adultos desenvolvidas nos idos dos anos de 1960 no Brasil e estendida para outros países com o exílio de Paulo Freire. Nesse sentido, Carrilho (2010, p.11) destaca o modo como Paulo Freire produziu o conhecimento em suas práticas de alfabetização:

[...] Un rasgo central del método de alfabetización propuesto por Freire es que se basaba en una previa y rigurosa investigación, adelantada conjuntamente por expertos y por la población en proceso de alfabetización. Dicha "pesquisa" busca, por un lado, reconocer la problemática del contexto local donde se desarrollará la acción alfabetizadora y, por el otro, la percepción de dichas situaciones por parte de los potenciales educandos, sus necesidades sentidas, sus aspiraciones y sus expectativas $[\ldots]$ (universo temático).

Segundo Carillo (2010), o método freireano de alfabetização teria cunhado um procedimento que pode ser chamado de investigação temática. Os procedimentos metodológicos envolviam três procedimentos pedagógicos utilizados no conhecimento da realidade social dos educandos, de sua cultura, de seu modo de viver e de ver o mundo e os problemas existenciais: a investigação temática, em que se procura fazer um levantamento das principais questões existenciais que afligem a vida dos educandos; a tematização, que consiste em codificar essas questões em temas geradores da organização do conteúdo e das discussões; e a problematização, que seria o momento de diálogo coletivo, mediado pelos temas cotidianos e existenciais.

[...] Este descubrimiento del rostro singular de los sectores populares más acá de sus representaciones ideológicas, impuso la necesidad de comprenderlos en su densidad histórica y cultural; crece así el interés por reconstruir los procesos de su configuración como colectivos y actores sociales, de develar las claves de su identidad, de sus cosmovisiones y modos de ver la realidad y actuar sobre la misma [...]. (CARRILLO, 2010, p.15)

Lembra o autor que esses procedimentos podem ser encontrados nos livros Pedagogia como prática da liberdade e Pedagogia do oprimido, ambos escritos durante o período de exilo de Paulo Freire. Nessa direção, Scocuglia (2005) afirma que a visão freireana de ser 
humano, de mundo, de história e de educação assume o diálogo, a criticidade, a problematização e o exercício da solidariedade, em consonância com uma perspectiva humanizante e libertadora, construída a partir do mundo do oprimido.

Ainda no território do conhecimento, uma segunda experiência vivida no âmbito da produção do conhecimento efetuada pela EP, no curso de sua história, ocorreu por volta do fim do Século XX, nas décadas de 1980 a 1990, quando a EP precisou se redefinir, encontrar-se consigo mesma e registrar sua trajetória. Nesse processo de produção das memórias de seu fazer, a EP lançou mão de um dispositivo de pesquisa, largamente conhecido entre os educadores populares como Sistematização de experiências, definida como

[...] una modalidad de conocimiento de carácter colectivo, sobre prácticas de intervención y acción social que a partir del reconocimiento e interpretación crítica de los sentidos y lógicas que la constituyen, busca potenciarlas y contribuir a la conceptualización del campo temático en el que se inscriben [...]. (TORRES, 1999, p. 14).

A valorização e o uso da sistematização da experiência na educação popular resultaram de uma reflexão profunda sobre seus fundamentos, ou seja, as premissas teórico-metodológicas que lhe deram origem, como, por exemplo, as oferecidas pelo Marxismo e pela Teologia da libertação. A questão da luta de classe, da libertação dos oprimidos e da consciência política, que norteou as bandeiras de luta das classes populares nos anos 60, 70 e 80, assentava-se em conceitos-chave como o de classe social e o de dominação e de exploração dos indivíduos por causa de sua inserção no mundo do trabalho, numa sociedade estruturalmente desigual, num cenário cultural elitizado, pautado na propriedade privada, nos interesses hegemônicos do capital, na restrição de direitos e na marginalização da cultura popular. Nesse sentido, destaca Carrillo (2010, p. 19):

[...] Ya fuera por la influencia de versiones renovadoras del marxismo o por el aporte de otras perspectivas teóricas, se puso en evidencia la estrechez de las versiones reduccionistas del marxismo que habían marcado las lecturas y orientaciones políticas de los setenta y ochenta [...].

Outra via de reconhecimento da presença da ética do cuidado na educação popular se encontra na esfera sociopolítica, impregnada da diversidade de demandas vinculadas à melhoria da qualidade de vida de diferentes categorias de sujeitos sociais. Referimo-nos às frentes de lutas em favor da efetividade de direitos consagrados como direitos públicos subjetivos, largamente reconhecidos na ordem geral dos direitos humanos. Em outras palavras, o cuidado ético da 
educação popular em criticar os processos e as situações existenciais, pautados em práticas discriminatórias, excludentes e dominadoras, que afetam diretamente a dignidade humana e inviabilizam a vivência cotidiana de práticas e experiências democráticas, libertárias e humanizantes.

Cabe mencionar o levantamento panorâmico dos movimentos sociais feito por Gohn (2011), que identificou 13 eixos temáticos que envolviam as seguintes lutas e demandas: luta pela questão urbana, pela inclusão social e por condições de acesso a moradia na cidade (movimento de moradia, movimento contra a violência urbana, movimento em favor da recuperação de estrutura ambiental); Mobilização pelas estruturas institucionais de participação na gestão político-administrativa da cidade; Movimento pela saúde; Movimentos de demandas na área do Direito; Movimentos sindicais contra o desemprego; Movimentos decorrentes de questões religiosas de diferenças crenças, seitas e tradições religiosas; Movimentos dos Sem-terra (na área urbana e na rural); Movimentos contra políticas neoliberais (contra reformas estatais que retiram direitos); grandes fóruns de mobilização da sociedade civil organizada (contra a globalização econômica; Fórum Social Mundial etc.); Movimentos de cooperativas populares; Mobilizações do Movimento Nacional de atingidos pelas Barragens e Movimentos sociais pela democratização da comunicação (FNDC).

Ainda na perspectiva de conferir ao stock a visibilidade de experiências disponíveis e possíveis proporcionadas pela educação popular nos últimos 40 anos, Hurtado (2006) elencou as principais contribuições da educação popular em vários níveis: como corrente prático-teórica que é viva, flexível, comprometida e dinâmica; assume um posicionamento crítico e autocrítico de seus fundamentos; cria de diversos projetos e processos, que se configuram como expressões do comprometimento e da efetivação de espaços de humanização, de vivência em processo de escolarização solidária e condições para desenvolver capacidades e potencialidades dos diversos sujeitos da aprendizagem; promove o desenvolvimento teórico e prático nos campos do conhecimento ligados a temas como meio ambiente, resolução de problemas, paz, gênero, poder local etc.; supera a crise de paradigmas, sem abandonar o anseio pela transformação humanizadora do processo civilizatório; reconhece que os espaços públicos são lugares em que a educação popular atua, que possibilitam sua influência no campo das políticas públicas; proporciona a participação dos membros do CEAAL em cargos de nível técnico-administrativo governamental, assim como em cargos públicos, tanto em nível municipal, quanto em cargos públicos de eleição popular; influencia significativamente as sociedades com processos sociopolíticos transformadores e possibilita a 
articulação entre os defensores e os educadores populares.

O ano de 1980 foi marcado por lutas, mobilização da sociedade civil organizada, efervescência dos movimentos sociais e surgimento de novos projetos para o Brasil. A rearticulação da sociedade civil e a união das forças de oposição política levaram a sociedade a um clima de esperança e a reconhecer que seria preciso retomar a democracia e a participação de todos nas decisões sociais e políticas. A população organizada entendeu que poderia promover mudanças e tornar-se sujeito histórico e protagonista no processo de democratização. Assim, podemos afirmar que a década de 80 foi o período marcado por fortes mudanças na conjuntura política e econômica, a qual foi o estopim para que os movimentos de lutas fossem considerados como de agitação popular, demonstrando o descontentamento social e a urgente necessidade de mudanças.

Considerando a via pedagógica, Mejía (2010) faz uma reflexão interessante sobre o modo como se faz educação no cerne da educação popular a partir do pensamento freireano. Segundo ele, o pedagógico requer o reconhecimento de que o ato educativo não é neutro, mas uma ação intencional que tem a realidade como matriz. E a depender das concepções de mundo e das ideologias do educador, sua prática é influenciada pelo que defende e valoriza e a que atribui sentido e significado. Portanto, educar é um ato essencialmente político, e a EP é um processo dialético de construção de conhecimento a partir da prática, com o fim de fazer um triplo movimento, a saber: pensar na prática, teorizar sobre ela e voltar para ela.

Assim, ao acionar as várias possibilidades pedagógicas, viriam junto as contribuições de diferentes gêneros de teorias e vice-versa. Isso significa que, com o acúmulo de saberes e de experiências pedagógicas, também viriam, como fundamento, as teorias críticas que as sustentam e conformam. Sobre isso, Mejía (2010, p. 38) assevera:

[...] La concepción de EP, a la vez que fundamenta desde su acumulado, incorpora elementos de diferentes tradiciones y concepciones críticas para hacer más completa su propuesta. En ese sentido, pudiéramos afirmar que en el terreno de las prácticas educativas y pedagógicas se van conformando híbridos, los cuales mezclan diferentes tradiciones [...].

Como se vê, o argumento de Mejía (2010) sinaliza uma espécie de fundamentação híbrida da EP, como se ela fosse constituída por meio de um jogo de escolhas das melhores alternativas de luta. Seria também vista como um movimento que não deve ser entendido como uma espécie de refundação ou reconceitualização, o que poderia sugerir a perda do horizonte identitário da EP, centrado na ética, na emancipação, na luta contra a desigualdade e a discriminação e, 
consequentemente, na afirmação intransigente dos direitos humanos.

É bem verdade que os novos embates proporcionados pela recomposição das forças conservadoras, defensoras do capital e das relações sociais de exploração e dominação apontam, a cada dia, novas questões e problemas. Porém isso não significa, de modo nenhum, uma revisão dos princípios da EP em função de sua submissão aos ditames do mercado e do capital globalizado. A onda neoliberal deve ser respondida não com a perda da identidade da EP, mas com a reconfiguração da agenda de luta das pedagogias críticas. Segundo Mejía (2013, p. 40),

[...] es en esa lógica que adquiere pleno sentido lo político-pedagógico como una forma de intervenir en la acción educativa, sea formal, no formal o informal, disputando la construcción que hace allí, con sus contenidos, métodos, didácticas, procedimientos, técnicas, el capital para generar su control en la esfera de lo educativo $[\ldots]$.

Ora, ao almejar a constituição de sujeitos transformadores, a EP pressupõe promover as potencialidades humanas necessárias para que possamos enfrentar os desafios da vida, da sociedade e do mundo que nos cerca. Isso exige que a EP esteja presente e atue em todas as modalidades e espaços sociais de aprendizagem possíveis, de modo que ela seja coadjuvante da mudança social. Esse é nosso maior desafio no contexto latino-americano. Nessa perspectiva, a EP se configura como um ato político e pedagógico. Sobre isso, Hurtado (2006, p. 154) referiu: “[...] ao reconhecer a dimensão política, estamos de fato decididos em favor de quem e de quê, portanto, contra quem e o que desenvolvemos nossas atividades educacionais? [...]".

\section{Considerações finais}

Certamente, o descrédito no horizonte de expectativas anunciadas na modernidade fez com que Santos formulasse uma espécie de mapa das racionalidades pós-modernas baseado em seis rotas, que são as seguintes: o saber e a ignorância (equilíbrio entre as vocações crítica e de cumplicidade), o desejável e o possível (consciência do excesso e do déficit), o interesse e a capacidade (multiplicidades de sujeitos), o alto e o baixo ou o solista e o coro (diálogo entre os diferentes), as pessoas e as coisas (valorização das relações intersubjetivas) e as microrracionalidades não são racionalidades mínimas (comunidades locais). Com base nesse roteiro, corroboramos o pensamento de Oliveira (2006, p. 59) de que

[...] o novo começo, do ponto de vista político, seria pensado como uma política pós-moderna, na qual as minirracionalidades da vida deixam de ser entendidas 
apenas como partes do todo e passam a ser totalidades presentes em múltiplas partes $[\ldots]$.

A perspectiva política pós-moderna indica que é necessário inventar novas subjetividades individuais e coletivas e novas formas de exercitar a cidadania e de promover a emancipação humana. Esses três marcos devem ser criticamente analisados e reinventados separada e articuladamente. Nesse sentido, uma das alterações incide, precisamente, na própria noção de político. Isso significa que, embora a política signifique exercício do poder, na ótica pós-moderna, o poder é uma espécie de relação social, cuja presença não se localiza em um ponto específico da formação social nem tem um centro difusor ou articulador do poder.

Esse entendimento de um poder que se pratica em todos os lugares e tempos, por ser uma maneira de se relacionar intersubjetivamente com o outro, traz a questão do reconhecimento das diferenças, do diálogo e da tomada de decisão compartilhada. Nesse sentido, a cidadania e a emancipação requerem o exercício pleno de uma democracia não mais simplesmente representativa, mas radicalmente participativa. Indivíduo e comunidade em rede, situados em tempos e lugares definidos, são os protagonistas locais e específicos do processo de emancipação. Assim, multiplicam-se os sujeitos, as reivindicações, as lutas, os territórios, as demandas e os processos alternativos de intervenção.

[...] o desenvolvimento do campo das alternativas sociais, considerando a desigualdade entre os paradigmas, coloca a exigência de aplicação da credibilidade das alternativas bem como das possibilidades inscritas na realidade, mas ainda apenas potenciais, de formulação de outras práticas [...]. (OLIVEIRA, 2006, p. 74)

Nesse cenário, o conhecimento compartilhado nos processos educativos teria a finalidade de proporcionar aos indivíduos e às coletividades interpretativas um conjunto de saberes e de experiências disponíveis em cada cultura e formação social que são necessários para entender o funcionamento e reestruturar os processos sociais de regulação no âmbito do Estado, do mercado e da comunidade, tendo em vista alargar o horizonte dos conhecimentos comprometidos com a emancipação, em seus níveis epistemológicos, estéticos e políticos, cuja centralidade da regulação e da emancipação estaria no eixo da emancipação, que seria a de criar as condições efetivas de uma vida decente para o maior número possível de pessoas aqui e agora.

Com efeito, o empoderamento dos sujeitos democráticos e inconformados com a precariedade da vida e com os sonhos da modernidade seria feito por meio de estratégias potencializadas pelas sociologias das ausências, das emergências e pela tradução, as quais, em

\begin{tabular}{l|l|l|l|l|l} 
C Revista Triângulo & Uberaba, Minas Gerais & v.12 & n.1 & p. 68 - 84 & 2019
\end{tabular}


tempos e em lugares diferenciados, politizariam as relações sociais vigentes através de diferentes temas, questões, vias e estratégias de lutas pelo exercício do poder emancipatório, materializado na participação efetiva de indivíduos e redes de sujeitos, imersos em situações concretas cotidianas dos mais diferentes tipos. Oliveira (2006, p. 143) enuncia que

[...] a questão da democracia deixa de estar restrita ao embate político em torno do Estado e do controle da atividade estatal para se dirigir ao conjunto das relações sociais no espaço doméstico, da comunidade, do mercado, da produção, e mesmo mundial. A horizontalização do conjunto das relações sociais e a sua refundação em processos de equalizados de interação, e não mais nas hierarquias apriorísticas seriam processos privilegiados de construção dessa democracia [...].

Ressalte-se, entretanto, que o contato com essas demandas tem suscitado uma questão relacionada à convivência com o diferente e ao investimento nas experiências disponíveis mais viáveis de acontecer, bem como de possibilitar uma qualidade de vida mais rica de possibilidades. Isso implicaria superar não somente a razão indolente e de sua lógica, como também as referidas estratégicas sociológicas, no sentido de utilizar outro procedimento mais apropriado para lidar com a diversidade de experiências disponíveis e possíveis. Apontamos, aqui, o que Santos denomina de tradução, conforme explica Santos (2002, p. 262):

[...] A tradução é o procedimento que permite criar inteligibilidade recíproca entre as experiências do mundo, tanto as disponíveis como as possíveis, reveladas pela sociologia das ausências e a sociologia das emergências. Trata-se de um procedimento que não atribui a nenhum conjunto de experiências nem o estatuto de totalidade exclusiva nem o estatuto de parte homogénea. As experiências do mundo são vistas em momentos diferentes do trabalho de tradução como totalidades ou partes e como realidades que se não esgotam nessas totalidades ou partes [...].

Nessa ótica, o trabalho de tradução, que incide sobre saberes, práticas e agentes, aconteceria com o emprego da hermenêutica diatópica em duas situações básicas. No caso dos saberes, a tradução seria feita por meio da [...] interpretação entre duas ou mais culturas, com vistas a identificar preocupações isomórficas entre elas e as diferentes respostas que fornecem para elas [...] (SANTOS, 2002, p. 262/263). Por sua vez, entre práticas e seus agentes, [...] o trabalho de tradução visa criar inteligibilidade recíproca entre formas de organização e entre objectivos de acção [...]. Esse duplo trabalho hermenêutico da tradução visa, conforme assinala Santos (2002, p. 266),

[...] esclarecer o que une e o que separa os diferentes movimentos e as diferentes práticas de modo a determinar as possibilidades e os limites da articulação ou agregação entre eles. Dado que não há uma prática social ou um sujeito coletivo privilegiado em abstracto para conferir sentido e direcção à história, o trabalho de 
tradução é decisivo para definir, em concreto, em cada momento e contexto histórico, quais as constelações de práticas com maior potencial contrahegemónico [...].

Embora Santos considere que a tradução e o procedimento viabilizam o reconhecimento das culturas silenciadas, ele afirma que esse trabalho requer um pressuposto fundamental e algumas condições necessárias para acontecer, caso contrário, a tradução acaba por se tornar um instrumento de implementação da razão indolente. Por isso, concordamos com Hurtado (2006, p.147-156) e com Mejia (2010, p. 206-211), quando enfatizam que é importante que os educadores, os pensadores e/ou os intelectuais da EP considerarem as mudanças visíveis no mundo capitalista globalizado, pois essas transformações têm influenciado o mundo do trabalho, o campo político, as práticas educativas formais e as organizações não governamentais, ou seja, o modo como as relações sociais vêm se estabelecendo. Considerando tal fato, os adeptos dessa proposta pedagógica precisariam pensar em novas alternativas e possibilidades de se fazer Educação Popular, sem perder de vista seus princípios e sem negar o contexto em que estão inseridos.

\section{REFERÊNCIAS}

ALCANTARA, Marcos Angelus Miranda de, CARLOS, Erenildo João. Algumas assinalações sobre a educação popular. Revista Temas em Educação, João Pessoa, Brasil, v. 27, n.1, p. 128-145, jan/jun 2018. Disponível em: http://www.periodicos.ufpb.br/index.php/rteo/article/view/33512. Acesso em: 8 março 2019.

CARLOS, Erenildo João. Semânticas da Educação Popular. In: Conceitos: Associação dos Docentes da Universidade Federal da Paraíba, João Pessoa. p. 66-76. 2003.

CARLOS, Dafiana do Socorro Soares Vicente; CARLOS, Erenildo João. Especulações sobre a moral em Kant e algumas implicações para as Ciências das Religiões. Ciências da Religião: história e sociedade, São Paulo, v. 13, n. 1, p. 13-31, jan./jun., 2015. Disponível em: http://editorarevistas.mackenzie.br/index.php/cr/article/view/7424/0. Acesso em: 12 dez. 2015.

CARRILLO, Afonso Torres. Educación popular y producción de conocimiento. La Piragua, México DF, CEAAL, n. 32, p. 8-25, 2010.

GOHN, Maria da Glória. Movimentos sociais na contemporaneidade. Revista Brasileira de Educação. v.6., n. 47, mai-ago., 2011.

HOLLIDAY, Oscar Jara. Ressignifiquemos as propostas e as práticas de Educação Popular perante os desafios históricos contemporâneos. In: PONTUAL, Pedro; IRELAND, Timothy (Org.). Educação Popular na América Latina: diálogos e perspectivas. Brasília: Ministério da Educação: UNESCO, 2006. P. 233-240.

HURTADO, Carlos Nunez. Contribuições para o Debate Latino-Americano sobre a Vigência e a Projeção da Educação Popular. In: PONTUAL, Pedro; IRELAND, Timothy (Org.). Educação Popular na América Latina: diálogos e perspectivas. Brasília: Ministério da Educação: UNESCO, 
2006. p. 147-156.

MEJIA J, Marco Raul. Las teorías críticas y las pedagogías críticas: fundamento de la educación popular - hacia una agenda de futuro. La Piragua, México DF, CEAAL, n. 32, p. 8-25, 2010. OLIVEIRA, Inês Barbosa de. Boaventura \& a Educação. Belo Horizonte: Autêntica, 2006.

SANTOS, Boaventura de Sousa. Para uma sociologia das ausências e uma sociologia das emergências. Revista Crítica de Ciências Sociais, Coimbra, 63, p. 237-280, out., 2002. Disponível em: http://rccs.revues.org/1285. Acesso em: 8 março. 2019.

\begin{tabular}{|l|r|}
\hline & Recebido em: 6 Fev. 2018 \\
\hline & Aprovado em: 18 Abr. 2019 \\
\hline
\end{tabular}

